\title{
El fin del siglo XIX y el ocaso de la industria regional: El caso de las tabacaleras nayaritas
}

\author{
Francisco Javier Castellón Fonseca, \\ Enedina Heredia Quevedo, \\ Bertha Alicia Villaseñor Palacios
}

Iscribir sobre la historia de la industrialización del tabaco en Nayarit, es retomar la fuente de donde, desde tiempos inmemoriales, ha surgido uno de los más fuertes impulsos económicos para esta región del occidente de México. En el transcurso de la historia, el cultivo masivo de este producto en las cálidas tierras del Nayar se encuentra ya durante la época colonial, aun durante los momentos de instrumentación del monopolio estatal del cultivo y del beneficio del tabaco por inspiración borbónica y, más aún, aparece hacia las medianías del siglo XIX cuando se retira el estanco del tabaco y la nación mexicana comienza a surgir con una serie de mercados regionales, poco relacionados entre si, pero con una amplia perspectiva de la idea de nacionalidad entre la población, producto de las constantes intervenciones extranjeras.

En términos económicos, el tabaco tiene características que propiciaron un mayor avance en las relaciones que los hombres establecen para producir los bienes necesarios para su existencia y bienestar. Por una parte, el solo cultivo de la planta hace imperativo que sea transformada para poder ser usada, lo que significa que a la par del uso de la tierra, se necesita una actividad artesanal o industrial que transforme el tabaco en cigarros, puros, rapé o polvo mezclado con otras sustancias para diversos usos, principalmente medicinales. Asimismo, las características físicas de la planta solanácea hacen que por su alto rendimiento, la mayor parte de la cosecha se destine a la venta o al intercambio. Lo antedicho explica que en tiempos de la Colonia, este cultivo fuera uno de los productos agrícolas cuya cosecha no se destinaba en su mayor parte al autoconsumo y que diera lugar a la existencia de numerosos talleres y sobre todo que originara la grandiosa Real Fábrica de Puros y Cigarros de la Nueva España, factoría que albergaba simultáneamente a 7000 trabajadores, entre pureros y cigarreros, que trabajaban manualmente, sin ningún tipo de tecnología mecanizada y a destajo, principalmente. Sin duda, la operación del establecimiento demuestra la necesidad que en ese tiempo se tenía de construir una organización industrial superior donde se pudiera concentrar el trabajo de los obreros cigarreros.

Hacia mediados del siglo XIX, cuando fue levantada la prohibición de sembrar el tabaco libremente, comenzaron a surgir un gran número de talleres que producían el llamado "cigarro de uña" en razón de que los operarios usaban uñas de latón para

1 Ma. Amparo Ros T., "La Real Fábrica de Puros y Cigarros: organización del trabajo y estructura urbana", en Alejandra Moreno Toscano (Coord.), Cd. de México. Ensayo de consirucción de una historia, México, INAH/SEP, 1978. 
enrollar y recortar los pitillos. Además, una vez seca la hoja, el tabaco se picaba a mano utilizando cuchillos y otros utensilios. Esas transformaciones muestran un avance en el proceso productivo: por un lado, la hoja ya no era utilizada en su forma simple sino que para su preparación se empleaban algunos instrumentos que, aunque sencillos, sustituian partes del trabajo de los obreros. Este tipo de producción fue el que predominó en todas las regiones tabaqueras de México hasta finalizar el siglo decimonónico. Se trabajaba principalmente en talleres artesanales, muchas veces de carácter familiar, que contaban con un maestro y varios obreros que elaboraban los diferentes productos del tabaco para un mercado estrictamente local. Podemos entonces entender por qué en las estadísticas porfirianas de 1900 se registran 766 establecimientos transformadores de la planta, diseminados por toda la República, y también por qué 10 años después, sólo quedaban $351,{ }^{2}$ pues el tamaño de los talleres les permitía desaparecer o fusionarse fácilmente.

En el entonces territorio de Tepic, por sus características climáticas, el cultivo del tabaco proliferó de tal manera que los productos derivados de las cosechas fueron internacionalmente reconocidos, como fue el caso de los de "El Tráfico" de Amado Fletes, cuyos puros y cigarrillos de tabacos labrados recibieron premios en exposiciones industriales en Atlanta (1898), en París (1900) y en Búfalo, Nueva York (1901). ${ }^{3}$ En general este tipo de pequeños talleres, cuyos capitales oscilaban entre los mil y tres mil pesos, se ubicaban principalmente en Tepic y Compostela, la región tabacalera mejor comunicada del territorio en esa época. Su objetivo principal era "la elaboración de puros y cigarros y la compra-venta de tabaco y artículos concernientes", tal como aparece en los registros públicos de la creación de las sociedades Rafael Peña y Compañia y La Flor de Chila, instaladas en Compostela, así como de la casa Vázquez M. y Cía. creada en Tepic en $1901{ }^{4}$

Un rasgo común de tales talleres es la asociación de personas que aportaban capital suficiente para hacerlos funcionar con otras que contaban con la experiencia y destreza suficiente para sacar adelante la producción, como aparece en las actas de instalación: en el caso de Rafael Peña y Cía., Crescencio de Avila era quien aportaba el dinero y el tabaco, el señor Peña "su industria y trabajo" con un salario de 15 pesos mensuales; ${ }^{5}$ en Vázquez $\mathrm{M}$. y Cía. los socios financieros eran Isidro Flores (cuya familia sería la principal impulsora de la producción industrial tabacalera y la de la habilitación financiera de los productores) y Leopoldo Vázquez, mientras que Cipriano Olivares por sus "conocimientos periciales" era considerado socio industrial con un sueldo de 25 pesos mensuales. ${ }^{6}$ Asimismo, en La Flor de Chila, donde se comerciali-

\footnotetext{
2 El Colegio de México, Estadísticas económicas del Porfiriato. Fuerza de trabajo $y$ actividad económica por sectores, México, El Colegio de México, Seminario de Historia Moderna de México, s.f., p. 114.

${ }^{3}$ Pedro López González, Mosaico histórico de la ciudad de Tepic, Tepic, Centro Regional Bancomer, 1979, p. 75.

Registro Público de la Propiedad en Tepic (en adelante RPPT), Ramo Comercio. Libro 4. Fojas 27 y 33.

${ }^{5}$ RPPT, Ramo Comercio, L. 4, F. 13.

- RPPT, Ramo Comercio, L. 4, F. 27, Reg. 36.
} 
zaban las marcas Flor de Chila y La Soberana, el capital era aportado por la señora Refugio de Alba, y don Ignacio Regalado era el creador de las marcas y el que realizaba el trabajo industrial. ${ }^{7} \mathrm{El}$ nivel de subordinación de los artesanos con respecto de los que disponian de dinero era muy bajo, como se muestra en las condiciones pactadas en Vázquez M. y Cía. donde Cipriano Olivares, socio industrial, recibía como sueldo 25 pesos mensuales, mientras que la disposición de fondos mensuales de los señores Vázquez y Flores ascendía a 10 pesos cada uno. ${ }^{8} \mathrm{La}$ capacidad de estos pequeños talleres para cubrir el mercado no alcanzaba más allá de los límites propios del territorio de Tepic y de la ciudad de Guadalajara, pero su existencia fue premisa suficiente para que surgiera un nuevo tipo de transformación industrial del tabaco en la región nayarita, con establecimientos mecanizados que utilizaban una gran cantidad de obreros, que contaban con una gran capacidad financiera y penetraban mercados, aunque regionales, más grandes que los de los talleres artesanales.

Ahora bien, como ya se ha mencionado, la desaparición de los pequeños talleres era un proceso simple, por la mínima cantidad de capital involucrada y por su gran dependencia del maestro artesano para el funcionamiento. Comienzan en ese momento a operar las dos fábricas cigarreras que existieron en Nayarit hasta la primera mitad del presente siglo y que marcaron el límite entre la vieja y la moderna estructura de producción industrial que caracteriza hoy al beneficio del tabaco en el estado. En este sentido, puede tomarse la idea de que en términos económicos del siglo XIX, centuria de fuertes transformaciones tanto para la región como para el país entero, terminó no en 1900 , sino varios años después, cuando se produjeron grandes cambios que revolucionaron la economía, la política y la sociedad de México y sus regiones.

En Nayarit, el limite entre lo artesanal y lo moderno industrial lo fijan en lo que a la industria del tabaco se refiere, esas dos casas: La Sin Rival, que tenía su centro de operaciones en Acaponeta, al norte del estado, y la cigarrera de los hermanos Flores que posteriormente fue denominada Cigarrera de Tepic, S. A. Ambos negocios utilizaron maquinaria moderna, se acogieron a las leyes nacionales en materia industrial, financiaron a productores tabacaleros y vendieron sus propias marcas en mercados regionales muy amplios.

La fábrica La Sin Rival, ${ }^{9}$ propiedad del señor Alejandro Gallardo Mitre, nació directamente de la estructura artesanal, ya que al ser fundada en el año de 1912, operaba como un pequeño taller donde dos obreras procesaban el tabaco en forma manual con el auxilio de uñas de latón.

Hecho importante para entender el origen de La Sin Rival es el de que su fundador y propietario trabajara en los Estados Unidos como obrero industrial en refinerias, cigarreras y otras industrias,

7 RPPT, Ramo Comercio, L. 4, F. 33, Reg. 38.

8 RPPT, Ramo Comercio, L. 4, F. 27, Reg. 36.

9 La información sobre esta fábrica nos fue amablemente proporcionada por don Alejandro Gallardo Diaz mediante varias entrevistas con él y miembros de su familia, y con el acceso a su archivo familiar. 
adquiriendo quizá los impulsos de un espíritu empresarial aventurero en Los Angeles o San Francisco. Posiblemente también la compañía de los técnicos de Las Cucharas Mining Company, instalada en Huajicori y donde el joven Alejandro pasó algunos años, le hiciera nacer la pasión por la disciplina y la productividad del trabajo industrial. Esta experiencia en el trabajo productivo, en el ámbito de las relaciones laborales y en el uso de tecnologia moderna era trascendental para el paso a un nuevo tipo de fábrica, con un carácter más definido en las relaciones obrero-capitalista. De esta manera, después de haber instalado su taller que no hacía sombra alguna a los talleres porfirianos de puros y cigarros del territorio hacia 1918 , la fábrica adquirió las dos primeras máquinas productoras de cigarros de uña y posteriormente se compraron en los Estados Unidos ocho máquinas de marca Excelsior Rapid, de procedencia alemana, con capacidad de 1000 a 1200 cigarros por minuto. Toda la década de los veinte fue de continuo crecimiento en términos financieros y productivos para la cigarrera. En 1930 , la fábrica contaba, además de con la maquinaria ya mencionada, con el trabajo de 185 obreros (110 mujeres y 75 hombres) que trabajaban dos turnos tanto en la elaboración de cigarrillos como en las labores de preparación del tabaco, esto es, en el secado, desvenado y deshebrado.

Por otro lado, además de fábrica de cigarros, La Sin Rival se fue convirtiendo en un conjunto de establecimientos donde se producían materias primas auxiliares para la fabricación de cigarros, aparte de sus propios trabajos comerciales: una imprenta, donde se elaboraba papel para cajetillas y envolturas; un aserradero de donde se obtenian las cajas de madera para empacar los paquetes de cigarros; una compañía de luz, un trapiche y un pequeño ingenio azucarero. Todo ello da cuenta de su importancia económica, altamente significativa en ese tiempo, puesto que generaba un buen número de empleos y un pequeño mejoramiento en las condiciones de vida de campesinos y obreros, pues a estos negocios cuya organización se asemejaba a una mínima integración horizontal que abarataba costos, se añadía el inicio de una integración vertical que convertía a don Alejandro en habilitador, financiero y comprador único de las cosechas de tabaco de los campesinos de la zona norte de Nayarit, principalmente de Tecuala y Acaponeta. Como consecuencia, se produjo una mayor actividad económica y comercial en esa zona, que además fue de las primeras beneficiadas por la introducción del ferrocarril que permitió a La Sin Rival vender sus productos en Sinaloa y Sonora por intermedio de la casa comercial Lizárraga de Mazatlán.

La Cigarrera de Tepic proviene de las inversiones realizadas en la década de los veinte por la sociedad mercantil de los hermanos Flores, familia que tenía amplios intereses en predios urbanos y grandes extensiones rurales, a diferencia del origen del capital de la familia Gallardo. Estas condiciones dieron lugar a la existencia de una relación estrecha con los productores de tabaco. No hay que olvidar que para esos años en Nayarit aún existian personas que poseían amplias propiedades en el campo. Con esta base lograron levantar la fábrica más grande y moderna del estado de Nayarit en las primeras cuatro décadas del siglo XX.

En 1935, la empresa cigarrera de los hermanos Flores se convir- 
tió en la sociedad anónima Cigarrera de Tepic, S. A. para acogerse a los beneficios otorgados por una ley estatal de protección a la industria, promulgada por el gobierno del estado en turno. ${ }^{10}$ Tales beneficios consistian fundamentalmente en la exención de impuestos, que deberia justificarse por un sustancioso aumento de la inversión en maquinaria y por un fuerte aumento en la producción que en esos años se estimaba en 16 millones de cajetillas anuales y que se elevó en un $75 \%$ con la adquisición de maquinaria encajetilladora procedente de la American Machine Foundry Co. de Brooklyn, Nueva York."

A diferencia de La Sin Rival el giro de las actividades de la compañía Cigarrera de Tepic, S. A. fue el siguiente: elaboración y fabricación de cigarros, envolturas, empaques o encajetillado; adquisición de materia prima para estos objetos y la maquinaria respectiva $y$, finalmente, refacción a los productores de tabaco del país. El capital social inicial era de cien mil pesos, dividido en 100 acciones de 1000 pesos cada una, de las cuales los hermanos Flores poseían 91 y otros tres socios eran propietarios de 3 acciones cada uno. ${ }^{12}$

El mercado cubierto por los productos de la Cigarrera de Tepic pronto rebasó los límites del estado, llevándolos a conectarse y coordinarse, en busca de canales para sus productos, con la compañia Cigarrera de Occidente de Guadalajara donde tuvieron participación en el capital. ${ }^{13}$ Las marcas que dieron prestigio regional fueron los famosos cigarros Excélsior, en sus diferentes tipos: Papel Arroz, Extras, Primeros y Número 15. La estructura de esta fábrica tiene un aspecto más cercano a una empresa de tipo capitalista, con perspectivas de desarrollo más amplias que las de los pequeños talleres existentes a principios de siglo e inclusive que las de la fábrica del señor Gallardo, quien mantenía una vinculación de tipo paternalista en el trabajo, con restricciones de tipo moral y familiar hacia sus obreros, ${ }^{14}$ a diferencia de Cigarrera de Tepic que se relacionaba con sus obreros mediante contratos de trabajo.

En muchas regiones de México, este tipo de estructura industrial llegó a su fín al afianzarse el proceso de consolidación del mercado interno nacional durante el periodo de las reformas cardenistas y el consiguiente proceso de industrialización del país. En el caso de las cigarreras nayaritas tuvo variantes interesantes de acuerdo a los casos. En general, en las dos fábricas estuvo presente el fantasma de los capitales que ya actuaban entonces en el mer-

${ }^{10}$ RPPT, Ramo Comercio, L. 6, F. 154, Reg. 228.

11 "Resolución de reducción de impuestos a los señores Flores Hermanos, propietarios de la fábrica denominada 'Cigarrera de Tepic'", en Periódico Oficial, órgano del gobierno del Estado de Nayarit, Tepic, miércoles 25 de marzo de 1936, núm. 25.

12 RPPT, Ramo Comercio, L. 6, F. 150, Reg. 227 p.

13 Entrevista con el C. P. Roberto Gutiérrez, contador general de Cigarrera de Tepic el día 10 de septiembre de 1986, y con el Ing. Raúl Flores Carrera el día 2 de septiembre de 1986.

14 En las entrevistas que sostuvimos con él, don Alejandro Gallardo nos explicó que su padre retenia del pago de sus obreros un porcentaje que pagaba directamente a la familia del trabajador para evitar que éste lo despilfarrara. Asimismo, encabezaba campanas para cerrar los antros de vicio en Acaponeta, organizaba equipos de beisbol que él mismo manejaba, etcétera. 
cado cigarrero nacional y que tenían una infraestructura y estrategia de carácter transnacional, como El Aguila y La Moderna, ambas filiales de la British American Tobacco Co., y que para la década de los treinta ya se habían introducido a las regiones tabacaleras nayaritas mediante el funcionamiento de la Compañía Comercial Nayarita, S. A. que financiaba y compraba la cosecha a los productores costeños.

En el caso de La Sin Rival, a mediados de la década de los treinta don Alejandro Gallardo habia recibido la primera oferta de compra de su fábrica de parte de la compañia El Aguila mediante la intervención del diputado José Ledón a la que contestó negativamente. En esos años se gestaba el proceso de conformación del mercado interno nacional que, lógicamente, beneficiaba al sector de la burguesia nacional que lo construia, afectando fuertemente a los grupos de pequeños empresarios regionales que mantenian sus espacios productivos locales. Este proceso se agudizó por la política oficial seguida por el gobierno de Lázaro Cárdenas de estimular los movimientos reivindicativos de los trabajadores, lo cual al mismo tiempo que ampliaba el consenso social del Estado, dotaba de un fuerte sustento de demanda efectiva para el proyecto industrializador. ${ }^{15}$ Para La Sin Rival este fenómeno integrador fue letal. Por un lado, al negarse el señor Gallardo a vender su fábrica a El Aguila, su mercado regional, como los de las demás empresas locales, empezó a verse invadido por las marcas nacionales de cigarros como los Bohemios, Belmont, Tigres, Alas y Faros que, paralelamente a una campaña publicitaria de grandes alcances, desplazó pronto a los cigarrillos locales. Por otra parte, la actuación de las fuerzas sindicalistas dirigidas en Acaponeta por un hijo del constituyente Juan Espinoza Bávara, que abanderaron un movimiento contra todos los establecimientos del señor Gallardo, originó la venta de casi todos sus establecimientos pues don Alejandro, con todo el odio que su actitud paternal exigia, prefirió cerrar e indemnizar a los trabajadores aliados al movimiento. Fue éste un golpe definitivo a la prosperidad de La Sin Rival y de los negocios aledaños del mismo propietario. De esta forma, sólo quedaron 12 trabajadores fieles a la familia Gallardo que continuaron operando en grado minimo la fábrica y la imprenta, consumiéndose lentamente la actividad económica de esas unidades de producción. Finalmente Cigarrera La Moderna al instalarse en Tepic, compró la maquinaria de la diezmada factoría de Acaponeta, que a principios de la década de los cincuenta, sólo producia marginalmente para un mercado de personas mayores que no se acostumbraban a los nuevos aromas.

En lo que se refiere a la compañía Cigarrera de Tepic, S. A., el final fue menos patético. Como ya se había visto, esta empresa se adecuaba constantemente, en términos de tecnologia y de política laboral, a los cambios que experimentaba en esa época la estructura socioeconómica de la región y del país, lo que le permitió asegurar su permanencia y rentabilidad dentro de la industria nayarita, cosa que logró a principios de los años cincuenta, cuando

is Este proceso estâ muy bien descrito por Victor Bravo Ahúja y Marco A. Michel, "Alianza y dominación: México 1930-1946", en Historia y sociedad, México, núm. 9, p. 31-51. 
mediante negociaciones que se mantuvieron en secreto para la opinión pública, los accionistas de La Moderna compraron a Cigarrera de Tepic sus instalaciones, marcas y maquinaria, utilizando los mecanismos que las empresas transnacionales pusieron en acción durante esa época para penetrar el mercado e instalarse en México. La intención de Cigarrera La Moderna con esa adquisición era bastante clara: mantener un centro de operaciones de carácter productivo, financiero y administrativo cerca de las principales regiones abastecedoras de materias primas. Las condiciones de la compra de Cigarrera de Tepic son aún desconocidas, pero se llegó a comentar que los hermanos Flores habían vendido su fábrica a El Aguila en cinco millones de pesos, transacción ocurrida en agosto de 1951 pero presentada a la opinión pública como una modernización de la maquinaria para contrarrestar a los diarios locales que en esas fechas destacaban las maniobras de instalación de máquinas cigarreras procedentes de Virginia, E. U., en sustitución de las viejas de la American Machine Foundry. En realidad, estos cambios técnicos fueron el primer paso de La Moderna para instalarse en Tepic. ${ }^{16}$ Por otra parte, aunque el convenio de venta nunca fue hecho público, trascendió que la única condición de venta impuesta por la familia Flores fue que la transnacional mantuviera la producción de la marca Excélsior que había dado prestigio a la fábrica de Tepic, condición que sólo se cumplió durante los primeros años de operación de La Moderna, dejando como único vestigio público de Cigarrera de Tepic el anuncio pintado en mosaico de los cigarrillos Excélsior ubicado en céntricas calles de la capital nayarita.

Con la operación de venta de Cigarrera de Tepic, se cierra para Nayarit toda una época de trabajo artesanal y manufacturero del tabaco, y se entra de lleno a la estructuración de gran industria que hoy distingue a la cigarrera instalada en Tepic. Sin duda, el ciclo iniciado en el siglo XIX caracterizado por una economia de trabajo manual, con tecnología rudimentaria, con relaciones obrero-patronales poco definidas, quedó atrás, y con él normas económicas que daban un fuerte tinte regionalista a cualquier actividad. Entra, a mediados de este siglo, un nuevo tipo de trabajo productivo, de relaciones industriales y de mercados para los productos nacionales. En suma, el fin del siglo XIX significó, a todas luces, la imposición de la nación, del país, sobre sus regiones, en grandes aspectos de la vida económica y social de México.

is "No hay venta; renovación de maquinaria", en El Nayar, 9 de agosto de 1951. 